\title{
Research of Tourism Development from the Perspective of Industrial
}

\author{
Cluster \\ Yanyan He \\ College of Management, Jiangxi University of Technology, Nanchang Jiangxi 330098
}

\begin{abstract}
With the rapid development of IT, tourism has had many complicated problems in the process of developing towards the fine and deep orientation. IT reform has made the same fields closer in relationship and cooperation among different fields is also gradually deepened. Due to its high correlation, tourism has great advantage in the development of industrial cluster. This paper makes the statement concerning the industrial cluster of tourism, analyzes the features and existing problems of tourism cluster in the current economic environment and proposes the favorable opinions and suggestions of the cluster development of tourism so as to provide significance theoretical opinions for the development of tourism in our country.
\end{abstract}

Key words- tourism; cluster; existing problems; solution

\section{INTRODUCTION}

Since the reform and opening up, the tourism economy in our country rapidly develops and the industrial scale keeps enlarging. The development of tourism is the important link of structural optimization of the industry. It has become an issue worth studying as to how to effectively and fully develop and utilize the special tourism resources with regional advantages and further turn them into industrial competitiveness and gain effects. The competitive advantages that industrial cluster possesses are helpful to improve the competitiveness of regional tourism. Hence analysis and research of tourism through the theory of industrial cluster is of great significance for the development of tourism and further improvement of its competitiveness.

\section{Research of Importance of Developing Tourism}

Tourism is regarded as a kind of necessity and consumer goods in life, the contents of which keep enriching with the constant development of economy and the form of which becomes diversified with the improvement of productivity. Tourism is closely related with other industries. Hence developing tourism is of great significance for the optimization of the regional industrial structure. Its important status in development national economy is embodied in the following aspects: boosting the development of other industries, improving the employment rate; narrowing the regional economic gap; maintaining sustainable development; increasing the earnings in foreign exchange etc.

First of all, boosting the development of other industries. Due to its high correlation with other industries, tourism plays a key role in boosting its related industries, directly embodied in transportation, accommodation, catering and retail industry and indirectly embodied in urban and rural construction and culture etc. Tourism is gradually at the central status in the cluster of tertiary industry.

Second, improving the employment rate. According to the statistics of World Tourism Organization, one more direct employee in tourism department will bring five more employment opportunities to the whole society. Therefore, greatly developing tourism can greatly boost the improvement of employment rate and increase of employees. Tourism belongs to labor-intensive industry; 
most of the tourism products are embodied through the form of labor service. Tourism and its directly related industries mostly belong to the tertiary industry, which has low requirements of the cultural levels of human resources. The higher education in our country has not been fully popularized. For the group that has not received higher education, tourism and its related industries will embrace them. Hence, greatly developing industry is of great help to solve the employment issue of the surplus population.

Third, narrowing the regional economic gap. In the current phase, the regional economic development in our country is severely out of balance; the gap between the South and North, the West and the East is huge. The middle and western regions, relatively backward in economic development, possess a great number of humanistic and natural tourism spots, which have great development potential. The development of tourism has the advantages of less investment and quicker repayment; it can also boost the development of other related industries. According to the statistics of World Tourism Organization, one yuan in tourism will lead to 4.3 yuan in other industries. Hence, greatly development regional tourism can greatly boost the economic growth in the backward regions and thus gradually narrow the regional economic gap.

Fourth, maintaining sustainable development. Tourism is reputed as smokeless industry. Developing industry brings little burden to the environment; tourism is a natural industry of sustainable development. However, while developing tourism, we must protect the environment of the scenic spots and the urban environment. Boost the sustainable development of national economy with that of tourism.

Fifth, increasing the earnings in foreign exchange. Tourism has obvious advantages in non-trade foreign exchange field, mainly shown in the following aspects: not restricted by the tariff, not restricted to non-tariff barrier, not causing trade fiction and convenient local foreign exchange. With the deepening of the global economic integration and the improvement of the international status of our country, the income of international tourism in our country gradually increases. Developing tourism will become the important means of export and foreign exchange and the important way of balancing international income and expense.

\section{Overview of Tourism Cluster}

\section{Concept}

Tourism cluster refers to integration of industrial chain, geographical space, development evolution and strategic idea. Hence tourism cluster can be defined as tendency and process concentrated on geographical space of tourism attraction, related elements and market connected by network, product chain or strategy plan.

\section{Advantage}

The advantages of tourism cluster are mainly composed of industrial combination, locational brand, innovation and external economy etc. First of all, advantage of industrial combination. Tourism is closely related to catering, recreation, accommodation, transportation and retail industry, which are mutually overlapped and complementary. In the entire industrial chain of tourism, these enterprises connected by joint interest are gathered in the relatively small spatial scope and serve the same client, which have the relations of both cooperation and competition. Industrial cluster enables the related industries of tourism to combine and develop; the long-term cooperation and competition will lower the threshold of integration of different industries and thus improve the integration and development of tourism and other industries. Second, advantage of locational brand. Most of the enterprises in tourism cluster are middle-sized and small-sized enterprises; the capital disadvantages make them unable to make the brand. Industrial cluster well solves this problem, which takes advantage of the group strength to create the locational brand, further benefiting all the members of the cluster. Third, innovation advantage. Industrial cluster gathers many enterprises from different industries within smaller space, thus increasing the communications and exchanges of concepts, techniques 
and knowledge and creating favorable environment for innovation. Fourth, advantage of external economy. The enterprises in tourism industry are relatively concentrated, which can share the human resources and infrastructure in the cluster, thus reducing the cost of internal enterprises and forming external economic advantages.

\section{Classification}

Tourism cluster mainly includes two types: resource-oriented tourism cluster and professional market-oriented tourism cluster. Resource-oriented tourism cluster refers to the industrial cluster that focuses on special tourism resources with some support of the local travel agencies and supporting service industries in order to serve the tourists. This type of industrial cluster is destination-oriented; through integrating the resources, it provides the whole-set tourism products and services for the tourists. Due to the diversity of enterprises in the cluster, the resource-oriented tourism cluster is characteristic of both complexity and unsteadiness. The stability of tourism resources requires the resource-oriented tourism cluster to be led by the government; the formation of such tourism cluster is closely related to the economic development level; regions of less developed economy tend to have such type. Professional market-oriented tourism cluster refers to the tourism cluster that focuses on large-scale travel agencies with some support of the middle-sized and small-sized travel agencies; it is formed by the tourism elements. The relationship is set up based on labor division and coordination; the inter-dependency of the travel agencies is higher, thus forming effective advantage of resource complementarity. The deep cooperation of the homogeneous enterprises is good for share and innovation of resources. Such cluster tends to be large-scale and takes e-commerce as its platform, thus forming the comprehensive tourism network integrated with wholesale, agency and retail. Professional market-oriented tourism cluster higher requirements of the infrastructure and passenger source; hence its market mainly faces the economically developed regions.

\section{Problems and Solutions of Tourism Cluster}

1. Incomplete Management System

The scenic spots and regions lack the unified planning and management. Disordered management is not good for the formation and development of tourism cluster. In the tourism regions, departments and local governments cannot effectively coordinate with one another; multi-management and scattered operation can be seen here and there, making the regional tourism resources unable to be reasonably integrated and the entire planning of tourism resources unable to be effectively implemented. Some local governments also have severe local protectionism and issue the policies and regulations that protect the local tourism, which greatly hinders the coordination and development of tourism enterprises in different regions, increases cost burden to the correlated enterprises in the tourism industrial chain, enlarges the difficulty of trans-regional integration of tourism and does harm to the development of tourism industry. The solution is to issue the laws and regulations suitable for the development of tourism industry so as to guarantee the development of tourism cluster in system. Make overall planning, integrate the tourism resources of the same region and build the leading enterprises in tourism. While providing premium service for the domestic clients, face the world and attract more foreign tourists to China so as to promote the traditional Chinese cultures and make contributions to the economic development.

\section{Unobvious Agglomeration Effects}

The agglomeration effects of tourism cluster are restricted by multiple factors, which are closely related to policy support, tourism resources, locational conditions and transportation facilities etc. For the resource-oriented tourism cluster formed by different industries, it is highly dependent on tourism resources, transportation facilities and service facilities. Whether the transportation is convenient and whether the service facilities are complete directly influences the agglomeration effects of resource-oriented tourism cluster. The organic combination of different industrial is 
connected by economic interests. If the tourism resources cannot attract enough tourists, infrastructure and service measures cannot meet the tourism demands of tourists and the negative impact caused by service becomes frequent, it will greatly affect the agglomeration effects of tourism cluster. For professional market-oriented tourism cluster, the main factors that influences its agglomeration effects are the policy, laws, regulations and location conditions of local governments. The solution is to create core brands, strengthen the investment of tourism infrastructure and eliminate local protectionism so as to effectively integrate the trans-regional tourism resources, focus on tourism resources and fully exert the agglomeration effects of tourism cluster.

\section{Severe Homogenous Competition}

Most of the enterprises in tourism cluster are labor-intensive, which have low threshold and weak industrial barriers. It causes that the tourism cluster is highly receptive and most of the industries in the cluster are service suppliers with low technique levels. The weak barriers make the unnecessary competition increase, the repeated investment increase and the homogenous competition heated in the tourism cluster. Due to the high requirements of capital and technique, the upstream and downstream industry dominating in the tourism cluster develops slowly, leading a fault to the development between the upstream and downstream and immediate labor-intensive industries, making the industrial chain of tourism unable to be effectively linked up and thus hindering the development of tourism cluster. The solution is to make reasonable planning, adopt policy means to ultimately alleviate the disordered and malicious competition in tourism cluster and greatly develop the polar industries in the upstream and downstream so as to improve the abnormal development mode of large medium part and small ends of tourism industry and make tourism develop in a healthy and rapid way.

\section{Lack of Innovation Awareness}

Innovation is the momentum of development. Product innovation of tourism service is also the momentum for tourism cluster to develop. Actually, the tourism in our country lacks the innovative awareness that serves the product. Tourism is at its prosperous stage and thus brings abundant profit to the enterprises in the cluster. In addition, innovation requires a large number of human resources and material resources and assumes great risks. At the current phase, most of the enterprises in the tourism cluster in our country adopt the traditional development mode or just follow suit, which is unfavorable for the sustainable development of cluster. From another perspective, the enterprises in tourism cluster are often small in scale and limited in capital, thus unable to conduct product innovation and service innovation. Under such a development mode, enterprises in the cluster will soon be eliminated by the market. The solution is to encourage product and service innovation; governments have to provide effective support in the policy layer and enterprises have to place innovation in its development strategy.

\section{Conclusion}

Above all, tourism is the backbone industry in the tertiary industry. Greatly developing the tourism cluster is of major significance for the economic transformation of our country. Due to the high correlation of tourism, developing tourism cluster has profound influence on the service industry that focuses on tourism. In order to gain sustainable and healthy development, tourism must set up the concept of modern market, exert the different advantages of tourism resources in different regions, break the industrial barriers, form the regional and national tourism network and strengthen the agglomeration effects of tourism industry so as to attract the domestic and foreign tourists and boost the rapid development of tourism. 


\section{References}

[1] Wang Zhaofeng. Research of Development Feature of Tourism Cluster Based on Ecological Theory [J]. Resource \& Environment, 2008/02.

[2] Zhang Meng. Analysis of Restrictive Factors of Tourism Cluster Development--Taking the Example of Jiuzhai Magnitude Tourism Zone [J]. Tourism Tribune, 2006/02.

[3] Cao Xing. Representative Work of Research of Structural Optimization and Upgrade of Tourism from the Perspective of Industrial Cluster--Review of Wang Zhaofeng's Research of Structural Optimization and Upgrade of Tourism Based on
Industrial Cluster [J]. Journal of Hunan University of Technology (Social Science), 2011/02.

[4] $\mathrm{Du} \mathrm{Yu,} \mathrm{Qiao} \mathrm{Meihua.} \mathrm{Problems} \mathrm{and} \mathrm{Solutions} \mathrm{of}$ Tourism Cluster in Shanxi [J]. Economist, 2007/05.

[5] Xu Yan, Yin Hongmei. Current Situation and Solution of Rural Tourism Cluster of Guiyang [J]. Guizhou Agricultural Science, 2010/11.

[6] Li Shuangqing, Liu Jianping. Research of Competitiveness Improvement of Red Tourism from the Perspective of Industrial Cluster [J]. Social Sciences Review, 2014/06. 